\title{
The Effects of Breathing Behaviour on Crack Growth of a Vibrating Beam
}

\author{
Wenguang Liu $\mathbb{D}^{1}$ and Mark E. Barkey ${ }^{2}$ \\ ${ }^{1}$ School of Aeronautic Manufacturing Engineering, Nanchang Hangkong University, Nanchang, Jiangxi 330063, China \\ ${ }^{2}$ Department of Aerospace Engineering and Mechanics, The University of Alabama, Tuscaloosa, AL 35487, USA \\ Correspondence should be addressed to Wenguang Liu; liuwg14@nchu.edu.cn
}

Received 10 October 2017; Revised 28 January 2018; Accepted 7 February 2018; Published 11 March 2018

Academic Editor: Mahmoud Bayat

Copyright (c) 2018 Wenguang Liu and Mark E. Barkey. This is an open access article distributed under the Creative Commons Attribution License, which permits unrestricted use, distribution, and reproduction in any medium, provided the original work is properly cited.

\begin{abstract}
The effects of breathing behaviour on the dynamic response and crack growth are studied through a cracked cantilever beam. The main goal is to reveal the coupling mechanism of dynamic response and crack growth by employing a plain single-degreeof-freedom (SDOF) lumped system with the breathing crack stiffness and friction damping. The friction damping loss factor is derived by using Coulomb friction model and energy principle. Natural frequency, dynamic stress, dynamic stress intensity factor (DSIF), and crack growth are analyzed by case studies in the end. Results indicate that not only does the stiffness oscillates during crack growth corresponding to the physically open and closed states of the crack, but also stiffness and friction damping oscillate nonlinearly with crack growth. This behaviour induces not only nonlinear dynamic response but also nonlinear crack growth. It provides an approximate description of the nonlinearities introduced by the presence of a breathing crack. Therefore, it can be employed to improve the prediction precision of the crack identification and crack growth life of a cracked cantilever beam.
\end{abstract}

\section{Introduction}

Cantilever beam-like structures such as aircraft wings, engine blades, and rocket bodies are widely used in the aerospace engineering field. Cracks often generate on the surface of a beam when the beam-like structure is subjected to vibratory loading conditions. In order to ensure the safety and reliability of these beam-like structures, study on the dynamic response and crack growth is important to prevent catastrophic failures, now and in the future.

According to whether the crack is in the opening or closing state during working time, the crack model is classified into two types: open crack models or breathing crack models. As the name implies, open crack models are regarded as keeping the crack in the open state during motion. For example, Biswal et al. [1], Krawczuk and Ostachowicz [2], Papadopoulos and Dimarogonas [3], Ostachowicz and Krawczuk [4], Chondros et al. [5, 6], Heydari et al. [7], and Behera et al. [8] developed different kinds of open crack models so as to simplify the dynamic analysis for cracked beams. However, the open crack model is not accurate for a beam having huge excitation due to the crack closure effect. Especially when a beam is at its resonance state, even a very tiny force may stimulate a large dynamic response. Thus, Cheng et al. [9], Chondros et al. [10], Douka and Hadjileontiadis [11], Kisa and Brandon [12], Surace et al. [13], Chatterjee [14], Ruotolo et al. [15], and Nandi and Neogy [16] proposed breathing crack models so as to consider the transition state between the fully open and fully closed state of a crack. Compared with the open crack models, breathing crack modes are in better agreement with cracks in practical engineering systems. That is why most of the recent studies about the dynamic response and crack growth mainly focus on the breathing cracked beams. In this article, two breathing crack models are employed to derive the stiffness model of the breathing cracked beam. One is using the square wave function to express the stiffness model of a cracked beam, and another is using the harmonic function. The square wave function model considers that breathing process has either fully open or fully closed two states. But the harmonic function model takes the transition state between the fully open crack state and fully closed state into account. 

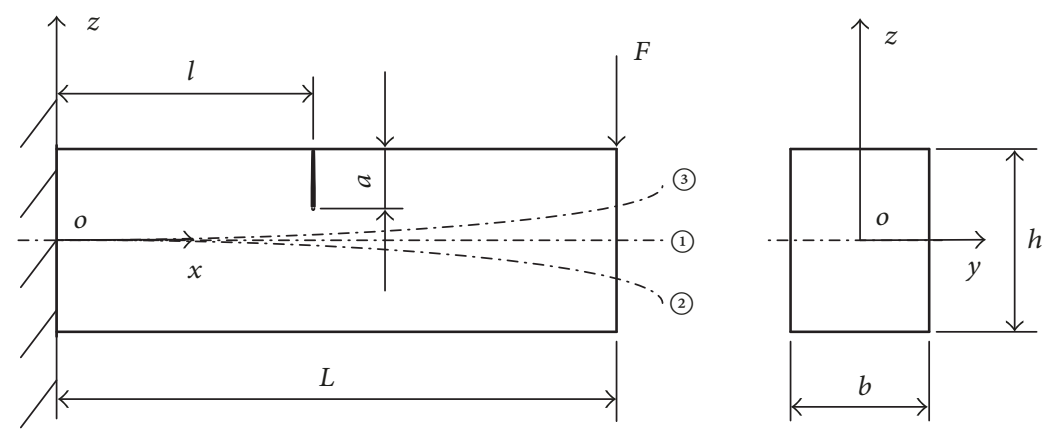

FIgURE 1: Model of a cracked cantilever beam, where $F$ is an exciting force and $a$ is the crack depth.

Through these crack models, the vibrational response of the cracked beam had been studied by many authors. Ostachowicz and Krawczuk [4] presented a means to analyze the effects of open cracks upon the natural frequencies of a cracked cantilever beam. Cheng et al. [9] investigated a nonlinear crack model to analyze the vibrational response of a cracked beam. Douka and Hadjileontiadis [11] and Liu and Barkey [17] studied the dynamic response of a breathing cracked beam so as to reveal the nonlinear behaviour. Kisa and Brandon [12], Zeng et al. [18], Zhang et al. [19], and $\mathrm{Ma}$ et al. [20] created a finite element model to analyze the vibrational response of a cracked beam. Ruotolo et al. [15] analyzed the dynamic response of a cracked beam under harmonic forcing by using a so-called closing crack model to represent the cracked element. Liu et al. [21] proposed a three-segment beam model having local flexibilities due to cracks to analyze the dynamic response of a beam having a closed, fully embedded crack. Shih and Chen [22] examined the coupling effect of the fatigue crack growth and dynamic response of a cracked shaft with straight-edge or elliptical arc cracks considered. Dentsoras and Dimarogonas [23-25] studied the crack propagation of a vibrating beam under different excitation. Results indicate that the stiffness value of a cracked beam when the closure effects are considered varies nonlinearly. It is changed periodically when a periodical force acts on the beam. The impacts of breathing behaviour on the stiffness of the cracked beam are reflected by a timevaried stiffness model. However, most of dynamic response analysis assumes that the crack remains static. The dynamic response varying with crack severity is ignored when carrying out crack growth analysis and the coupling effects between the dynamic response and the crack growth are generally not considered.

The coupling of the crack growth and the dynamic response is a complicated but important mechanism to the dynamic design and the damage tolerant design of a cracked beam working in vibration environment. However, at present, few works have been done concerning the coupling effects of the fatigue crack growth and the dynamic response. Most of the present works that have been done ignore the fact that the crack severity changes during vibration analysis. In fact, not only will the crack depth increase but also will the microslip of the crack surfaces that are produced when the closure effect is considered for a vibrating beam.
In this case, the friction force between the crack surfaces is introduced by the normal pressure forces. This friction force will do work over the microslide distance so that the energy dissipation is produced. When friction energy dissipation happens, damping is introduced. When a cracked beam works in a resonance condition, the friction damping will play a very important role in the dynamic response and crack propagation. This scenario happens frequently in equipment and structures. Therefore, resonance is one of the common reasons of equipment failures. Because the crack alters dynamic properties of the vibrating beam, the dynamic response analysis is often used to calculate the dynamic force applied to the cracked section of beam. These observations imply that the breathing behaviour is a complicated but a real very important factor to the damage tolerant design for a beam. Therefore, it is vital to understand the dynamic response changes caused by the crack growth and its effect upon the crack growth. But the previous research pays little attention to this problem. In order to discover the mechanism of friction damping and its effect on the dynamic response and crack growth, the critical detail is to set up a proper friction damping model for the breathing crack.

The present work is to analyze the first mode frequency of the cracked beam by the mentioned two stiffness models and Galerkin method, to derive a friction damping model for a breathing crack by energy principle and Coulomb friction model, and to discuss the dynamic stress response, stress intensity factor, and crack growth with friction damping loss factor included by case studies in the end.

\section{Vibration Equation of a Cracked Beam}

2.1. Single-Degree-of-Freedom (SDOF) System. In this article, an Euler-Bernoulli cantilever beam of 304 stainless steel (304SS) is considered. The material of the beam is assumed to be isotropic and homogenous. And a straight surface crack is assumed to be on the top edge. The coordinate, geometry, and dimensions of the beam are shown in Figure 1.

Ignoring the structural damping and the crack damping, the transverse dynamic equation of an elastic beam in the $x-z$ plane under a concentrated sine force $F$ can be expressed as

$$
E I \frac{\partial^{4} w}{\partial x^{4}}+\rho A \frac{\partial^{2} w}{\partial t^{2}}=F_{0} \sin (\omega t) \delta(x-L)
$$


Here, $w$ is the transverse displacement, $x$ is the coordinate, $t$ is time, $E$ is elastic modulus of material, $\rho$ is density of material, $I$ is the area moment of inertia of the beam's cross section about $y$-axis, $A$ is area of the cross section, $F_{0}$ is amplitude of the external harmonic force, $\omega$ is excitation frequency, and $\delta$ is the Dirac function.

Based on the composition of a forced dynamic response, the first mode does the most contribution. Therefore, only the first vibration mode of the cracked cantilever beam is considered in this article. Suppose that $W(x)$ is the vibration amplitude at $x$ position of the neutral axis of the cross section of beam and $T(t)$ is amplitude-time function at any position. The equation of motion of a single-degreeof-freedom (SDOF) system for the intact beam through Galerkin method can be expressed as

$$
m^{*} \frac{\partial^{2} T}{\partial t^{2}}+k^{*} T=F^{*}
$$

Here, $m^{*}$ is the generalized mass, $k^{*}$ is the generalized stiffness, and $F^{*}$ is the generalized force. They are given by

$$
\begin{aligned}
m^{*} & =\rho A \int_{0}^{L} W^{2}(x) d x \\
k^{*} & =E I \int_{0}^{L} \frac{\partial^{4} W(x)}{\partial x_{4}} W(x) d x \\
F^{*} & =F_{0} \sin (\omega t) \int_{0}^{L} W(x) \delta(x-L) d x .
\end{aligned}
$$

Based on the boundary condition of a cantilever beam, the vibration shape function of the first mode is given by [26]

$$
\begin{aligned}
W(x)= & \left(\cos \frac{1.8751}{L} x-\cosh \frac{1.8751}{L} x\right) \\
& -0.7341\left(\sin \frac{1.8751}{L} x-\sinh \frac{1.8751}{L} x\right) .
\end{aligned}
$$

Supposing that the damping of the beam composed of the material damping $\gamma_{m}$ and the crack damping $\gamma_{f}$, then the SDOF vibration equation of the cracked beam with damping can be modified as

$$
m^{*} \frac{\partial^{2} T}{\partial t^{2}}+c^{*} \frac{\partial T}{\partial t}+k^{*} T=F^{*}
$$

Here, $c^{*}$ is the damping coefficient; it is given by

$$
c^{*}=\left(\gamma_{m}+\gamma_{f}\right) \sqrt{m^{*} k^{*}} .
$$

Therefore, the cracked cantilever beam is simplified into a SDOF system as shown in Figure 2.

2.2. Stiffness Model of a Cracked Beam. When there is a periodic force $F$ acting at the free end of the cantilever beam as shown in Figure 1, the cracked beam will be stimulated to vibrate and the crack will alternate between open and closed states. This phenomenon is defined as the so-called breathing behaviour. It can be regarded as that the stiffness value of the

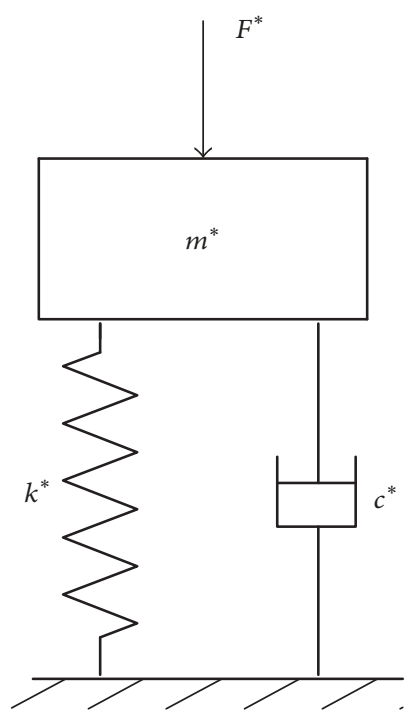

FIgURE 2: Equivalent SDOF model of the cracked cantilever beam.

breathing cracked beam varies with time between the stiffness of the beam as the crack is fully closed and the stiffness as the crack is fully open. Thus, the stiffness value of the breathing cracked beam can be expressed by

$$
k_{\mathrm{br}}(t)=k_{o}+\beta(t)\left(k_{c}-k_{o}\right) \text {. }
$$

Here, $t$ is the time, $\beta(t)$ is the breathing function, $k_{o}$ is the stiffness of the beam as crack is fully open, $k_{c}$ is the stiffness when the crack is fully closed, $k_{\mathrm{br}}$ is the stiffness for the breathing cracked beam, and $k_{c}$ is regarded as equal to the stiffness of the intact beam $k^{*}$ in this article.

In order to understand and simulate the open and closed state of the breathing crack, a square wave function is used during analysis. The square wave function is given by

$$
\beta(t)= \begin{cases}1 & 0<\omega t<\pi \\ 0 & \pi<\omega t<2 \pi .\end{cases}
$$

Here, the function means that, in one vibration cycle, when $0<\omega t<\pi$, the crack is in fully close state, and when $\pi<$ $\omega t<2 \pi$, the crack is in fully open state. That implied that the breathing process of the crack is divided into two states absolutely by the square wave function, either fully open or fully close, with no transition states between them. This is not the real situation in the beam, but it is helpful to understand the frequency of the breathing cracked beam.

If there is a sine excitation force $F$ applied to the beam, it is more reasonable to use a harmonic breathing function than to use a square wave breathing function. When the beam vibrates predominantly at its fundamental mode, the harmonic function is given by

$$
\beta(t)=\frac{1}{2}+\frac{1}{2} \sin (\omega t)
$$


Through (9) and (7), the stiffness model of the breathing cracked beam can be written as

$$
k_{\mathrm{br}}(t)=\frac{\left(k_{c}+k_{o}\right)}{2}+\frac{\left(k_{c}-k_{o}\right)}{2} \sin (\omega t) .
$$

From (10), it indicates that the stiffness of the breathing cracked beam is composed of the stiffness of open cracked beam and the stiffness of closed cracked beam. It can be seen from Figure 1 that, in case of $\omega t=n \pi,(n=1,2,3, \ldots)$, the axis $x$ of the beam stays at (1) position, and the crack is in half open state. In case of $\omega t=2 n \pi-\pi / 2$, the axis $x$ of the beam reaches (2) position and the crack is fully open. In case of $\omega t=2 n \pi+\pi / 2$, the axis $x$ of the beam reaches (3) position and the crack is fully closed.

Ignoring the shear force, a cracked cantilever beam can be regarded as two intact beams that are connected by a torsional spring as shown in Figure 3. Therefore, the stiffness of the torsional spring $k_{T}$ due to crack can be obtained from the equation developed by Dimarogonas et al. [27] as

$$
k_{T}=\frac{E b h^{2}}{72 \pi(L-l)^{2}\left(1-v^{2}\right) \Phi} .
$$

Here, $l$ is the distance of the crack from the fixed end; $L, b$, and $h$ are the respective length, width, and height of the beam; $v$ is the Poisson ratio of the material. The function $\phi$ is given by

$$
\begin{aligned}
\phi= & 0.629\left(\frac{a}{h}\right)^{2}-1.047\left(\frac{a}{h}\right)^{3}+4.602\left(\frac{a}{h}\right)^{4} \\
& -9.975\left(\frac{a}{h}\right)^{5}+20.295\left(\frac{a}{h}\right)^{6}-32.993\left(\frac{a}{h}\right)^{7} \\
& +47.041\left(\frac{a}{h}\right)^{8}-40.693\left(\frac{a}{h}\right)^{9}+19.6\left(\frac{a}{h}\right)^{10} .
\end{aligned}
$$

Therefore, the stiffness of the open cracked beam can be calculated by

$$
k_{o}=\frac{k_{T} k_{c}}{k_{T}+k_{c}} \text {. }
$$

\section{Friction Damping Model}

3.1. Sliding Friction Model. During crack propagation, the crack tip material will yield and then separate. When the material of the crack tip fractures, the crack will advance. According to the knowledge of materials mechanics, the yield failure of ductile materials often happens related to the maximum shear stress. And the maximum shear stress usually appears on the incline plane which forms a $45^{\circ}$ angle to the cross section of the cracked beam under tension stress state for most of steels. Therefore, test results of specimen with smooth surface often yield to some $45^{\circ}$ cross inclination strips as shown in Figure 4.

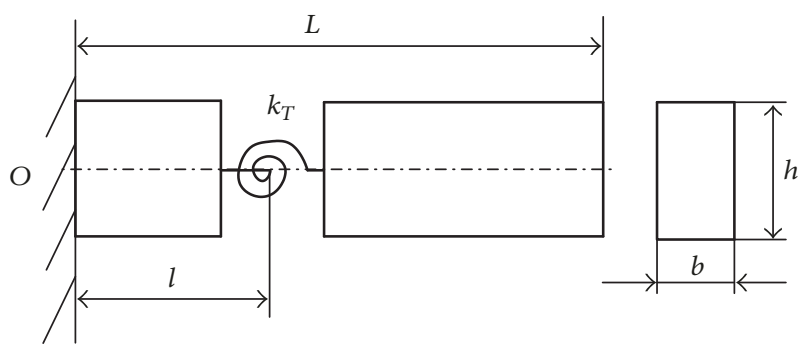

FIGURE 3: Stiffness model of the cracked cantilever beam.

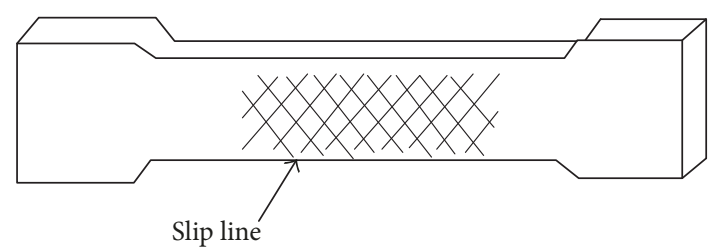

FIgURE 4: Yield slip line.

Take the Euler-Bernoulli beam having a breathing crack as the research object as shown in Figure 1. Suppose that the crack growth is just straight ahead driven by the dynamic response; it could be conceived that the cross-yield slip line with $45^{\circ}$ near the crack tip probably will appear on the surface as shown in Figure 5.

Before creating the sliding friction model for the breathing crack, some assumptions should be given at first as follows:

(1) The dynamic response of the cracked beam is stable.

(2) The energy dissipation of the cracked beam is produced just by the friction of the crack surface.

(3) The friction force at the semicrack depth as $Q$ point as shown in Figure 5 is employed to calculate the dissipated energy.

(4) The energy dissipation happens only when the crack is in the compressed zone.

(5) The friction force of the crack surfaces satisfies with the Coulomb model law.

(6) The total storage strain energy of the intact beam is equal to that of the breathing cracked beam.

Based on these given assumptions, the surface slide friction model of the breathing crack is set up as shown in Figure 6. In the frictional model, $F_{n}$ is the normal pressing force which is perpendicular to the cross section of beam and $F_{f}$ is the friction force between the crack surfaces. It is estimated by the normal stress of $Q$ point, a position of semicrack depth. The relative microsliding distance $d$ depends on the crack open distance (COD) at the semicrack depth position.

3.2. Damping Loss Factor. According to the geometry of the cracked beam as shown in Figure 5, the nominal stress of $Q$ point as the crack is fully close can be estimated by Hooke's law. It is given by

$$
\sigma_{n}=\left.0.5 E(h-a) \frac{\partial^{2} w}{\partial x^{2}}\right|_{x=l} .
$$




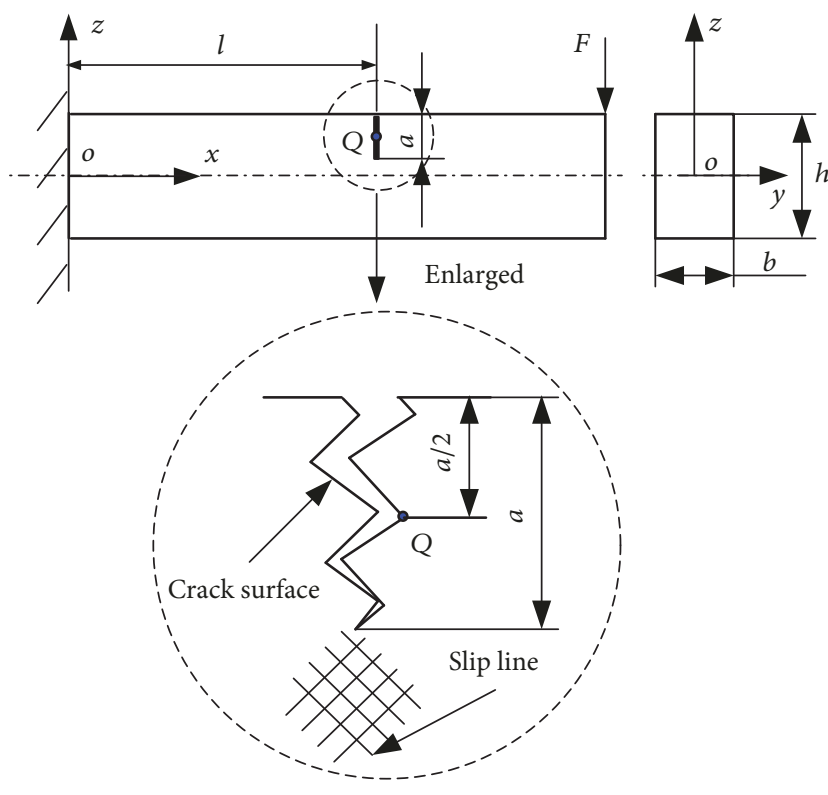

FIGURE 5: Crack growth road.

Therefore, the normal pressing force is obtained

$$
F_{n}=a b \sigma_{n} .
$$

Because the breathing crack will be opened gradually when it is in intensive zone and will be closed when it is in a compressed zone, the value of pressing force may exist during the half cycle relative to the effect of external harmonic force and the average pressing force $F_{\mathrm{av}}$ in one cycle is given by

$$
F_{\mathrm{av}}=\frac{1}{\pi}\left|\int_{0}^{\pi} F_{n} \sin (\omega t) d(\omega t)\right|=\frac{2 F_{n}}{\pi} .
$$

If the frictional coefficient of crack surfaces for 304SS is $\mu$, the friction force between the crack surfaces can be derived by the sliding friction model. It is given by

$$
F_{f}=\mu F_{\mathrm{av}} \cos 45^{\circ} .
$$

In each cycle, the breathing process of the crack from the open state to the close state includes 4 phases. If position (1) is the initial position as shown in Figure 1, a total breathing process includes (1) $\rightarrow$ (2) $\rightarrow$ (1) $\rightarrow$ (3) $\rightarrow$ (1). Only when the crack is in the compressed zone, the friction force will be produced. Based on the work-energy theorem for systems, the energy dissipation introduced by the sliding friction force between the crack surfaces in one vibration cycle is given by

$$
W_{C}=2 F_{f} d
$$

It can be seen from Figure 6 that the relative sliding distance between the crack surfaces depends on COD of $Q$

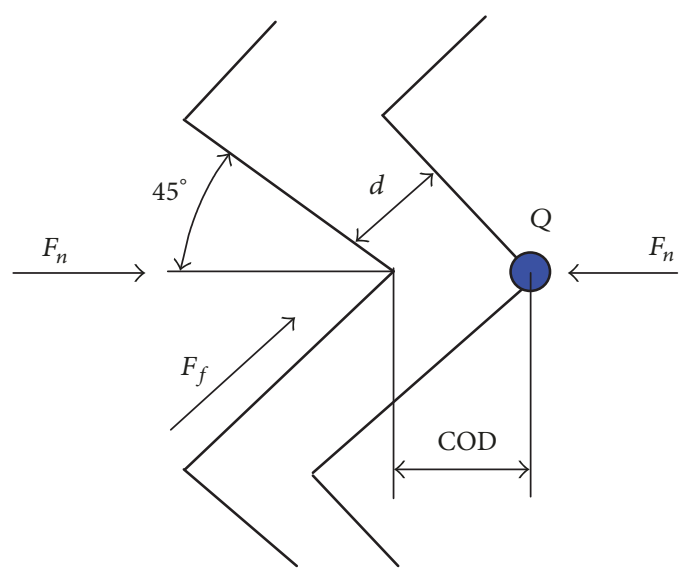

FIGURE 6: Friction model of crack surface.

point. An empirical formula for COD with $1 \%$ accuracy for any $a / h$ is given by Tada et al. [28]

$$
\mathrm{COD}=\frac{4 \sigma_{n} a}{E} V\left(\frac{a}{h}\right) .
$$

Here, the function $V(a / h)$ is given by

$$
V\left(\frac{a}{h}\right)=0.8-1.7\left(\frac{a}{h}\right)+2.4\left(\frac{a}{h}\right)^{2}+\frac{0.66}{(1-a / h)^{2}} .
$$

Figure 6 shows that the relation between COD and $d$ is

$$
d=\operatorname{COD} \cdot \cos \frac{\pi}{4}
$$

Therefore, the energy dissipation caused by the friction force within one vibration cycle is obtained

$$
W_{C}=\frac{4}{\pi} \frac{\mu}{E} a^{2} b \sigma_{n}^{2} V\left(\frac{a}{h}\right) .
$$

According to the energy principle and the assumptions, the strain energy storage in the cracked beam having rectangular cross section is given by

$$
\begin{aligned}
V_{\max }= & \int_{0}^{L} \frac{E I}{2}\left(\frac{\partial^{2} w}{\partial x^{2}}\right)^{2} d x \\
& +\int_{0}^{L} \frac{1.2(1+v) E I^{2}}{A}\left(\frac{\partial^{3} w}{\partial x^{3}}\right)^{2} d x .
\end{aligned}
$$

For a cracked beam, the friction damping loss factor $\gamma_{f}$ can be defined as

$$
\gamma_{f}=\frac{W_{C}}{2 \pi V_{\max }} .
$$


Therefore, the damping loss factor caused by the friction of the crack surfaces is obtained

$$
\gamma_{f}=\frac{2 \mu a^{2} b(h-a)^{2} V(a / h)\left(\left.\left(\partial^{2} w / \partial x^{2}\right)\right|_{x=l}\right)^{2}}{\pi^{2}\left(I \int_{0}^{L}\left(\partial^{2} w / \partial x^{2}\right)^{2} d x+\left(2.4(1+\nu) I^{2} / A\right) \int_{0}^{L}\left(\partial^{3} w / \partial x^{3}\right)^{2} d x\right)} .
$$

\section{Vibration Response Analysis}

4.1. Mode Frequency. If the generalized stiffness $k^{*}$ is replaced by the stiffness of the open cracked beam $k_{o}$, then the first mode frequency of the open cracked beam is also obtained. Therefore, the first mode frequency of the cracked beam corresponding to fully open and fully closed states can be predicted approximately by the following equation:

$$
\omega_{o, c}=\sqrt{\frac{k_{o, c}}{m^{*}}}
$$

Here, $\omega_{o}$ is the frequency of the open cracked beam and $\omega_{c}$ is the frequency of the closed cracked beam.

If the breathing behaviour is considered, the stiffness of the cracked beam varies with time within one vibration cycle. It is impossible to plug the stiffness model of a breathing cracked beam into the frequency equation (26) to analyze the mode frequency of the breathing cracked beam directly. But within one cycle, no matter which kind of the breathing function is used, the cycle period time will not change. If the square wave function is used, the vibration cycle time includes two parts. The prehalf cycle corresponds to the fully open crack, and the posthalf cycle corresponds to the fully closed crack. Therefore, the relation of the sine breathing behaviour and the square wave breathing behaviour must obey

$$
\frac{2 \pi}{\omega_{\mathrm{br}}}=\frac{\pi}{\omega_{o}}+\frac{\pi}{\omega_{c}}
$$

Here, $\omega_{\mathrm{br}}$ is the frequency of the breathing cracked beam. It is given by

$$
\omega_{\mathrm{br}}=\frac{2 \omega_{o} \omega_{c}}{\omega_{o}+\omega_{c}}
$$

4.2. Dynamic Stress Intensity Factor (DSIF). For a vibrating cracked beam, the crack propagation speed relies on not only the amplitude of dynamic stress response but also the crack depth. For an edge cracked beam as shown in Figure 1, ignoring the shear force, the beam endures bending load mainly. The crack will open as type I crack. In real engineering practice, mode I crack maybe is the most common crack model, and it is very sensitive to dynamic response. Therefore, the mode I crack is considered in this article. Based on the strength theory and Hooke's law, the nominal dynamic bulk stress at the top edge of the cracked beam under pure bending states can be estimated approximately by

$$
\sigma_{d}=\left.E \frac{h}{2} \frac{\partial^{2} w(x, t)}{\partial x^{2}}\right|_{x=l}
$$

Plugging the dynamic displacement response into the stress equation, we obtain

$$
\sigma_{d}=\left.E \eta Z_{\text {st }} \frac{h}{2} \frac{\partial^{2} W(x)}{\partial x^{2}}\right|_{x=l}
$$

Here, $Z_{\text {st }}$ is the static displacement, it is the ratio of the generalized force and the stiffness of the cracked beam; $\eta$ is the amplify ratio of displacement response; it is given by [26] and expressed by

$$
\eta=\frac{1}{\sqrt{\left(1-\lambda^{2}\right)^{2}+\left(\left(\gamma_{m}+\gamma_{f}\right) \lambda\right)^{2}}} .
$$

Here, $\lambda$ is the frequency ratio. When $\lambda$ is near to 1 , the beam is near or at resonance, the amplify ratio is very large, and the damping ratio plays important role in the resonance response and crack growth.

Based on the definition of stress intensity factor (SIF) in fracture mechanics, the SIF of the beam under pure bending can be defined by empirical formula

$$
K_{I d}=\sigma_{d} \sqrt{\pi a} F_{I}\left(\frac{a}{h}\right) .
$$

Here, $K_{I d}$ is SIF; $\sigma_{d}$ is the nominal dynamic bulk stress, $F_{I}(a / h)$ is crack shape function, and it is given by many authors in approximate expression as [28]

$$
\begin{aligned}
F_{I}\left(\frac{a}{h}\right)= & 1.122-1.40\left(\frac{a}{h}\right)+7.33\left(\frac{a}{h}\right)^{2} \\
& -13.08\left(\frac{a}{h}\right)^{3}+14.0\left(\frac{a}{h}\right)^{4} .
\end{aligned}
$$

The shape function is claimed to be of engineering accuracy for any $a / h<0.6$.

\section{Crack Growth Analysis}

5.1. The Modified Forman Equation. The parameters such as the crack closure effect, stress ratio, SIF range, critical SIF, and the threshold of SIF are considered for the model of crack 
growth, which is called the modified Forman Model [21]. This model is employed for crack growth analysis in this study and shown as

$$
\frac{d a}{d N}=B\left(\frac{1-f}{1-r} \Delta K\right)^{n} \frac{\left[1-\Delta K_{\mathrm{th}} / \Delta K\right]^{p}}{\left[1-\Delta K /(1-r) K_{c}\right]^{q}} .
$$

Here, $r$ is the stress ratio; $K_{c}$ is the critical SIF; $\Delta K_{\mathrm{th}}$ is the threshold SIF and $\Delta K$ is the stress intensity range; $N$ is the numbers of vibration cycle; $B, n, p$, and $q$ are fatigue properties of materials; $f$ is closure function and given by Newman Jr. [29]

$$
\begin{aligned}
& f \\
& \quad \begin{cases}\max \left(r, m_{0}+m_{1} r+m_{2} r^{2}+m_{3} r^{3}\right) & r \geq 0 \\
m_{0}+m_{1} r & 0>r \geq-2 \\
m_{0}-2 m_{1} & r<-2,\end{cases}
\end{aligned}
$$

where

$$
\begin{aligned}
& m_{0}=\left(0.825-0.34 \alpha+0.05 \alpha^{2}\right)\left[\cos \left(\frac{\pi S_{\max }}{\left(2 \sigma_{0}\right)}\right)\right]^{1 / \alpha} \\
& m_{1}=\frac{(0.415-0.071 \alpha) S_{\max }}{\sigma_{0}} \\
& m_{2}=1-m_{0}-m_{1}-m_{3} \\
& m_{3}=2 m_{0}+m_{1}-1
\end{aligned}
$$

The threshold SIF is given by

$$
\Delta K_{\mathrm{th}}=\Delta K_{\mathrm{th} 0}\left(\frac{a}{a+a_{0}}\right)^{0.5}\left(\frac{4}{\pi \tan (1-r)}\right) .
$$

Here, $\Delta K_{\text {th } 0}$ is the threshold SIF when $r$ is $0 ; a_{0}$ is the initial crack depth.

In these formulas, $\alpha$ is the constraint coefficient for plane stress or plane strain problem; $S_{\max } / \sigma_{0}$ is the ratio of the maximum stress and stress flow. For the constant amplitude loading, the increment of crack growth can be calculated by integrating (34). Because the stress relies on the crack depth, the exciting frequency, and the damping, the amplitude of dynamic stress response is assumed to be a constant value within one cycle. The incremental crack growth in each cycle can be estimated by (34). Then the crack depth after $i$ times cycle can be calculated by the superposition method and expressed as

$$
a_{i}=a_{0}+\sum_{j=1}^{i} \Delta a_{j}
$$

Here, $a_{i}$ is the total crack depth after $i$ times cycle and $\Delta a_{j}$ is the crack incremental of the $j$ th step vibration.

The incremental of crack growth within one vibration cycle is calculated by employing the modified Forman crack growth equation. It is expressed by

$$
\Delta a=B\left(\frac{1-f}{1-r} \Delta K\right)^{n} \frac{\left[1-\Delta K_{\mathrm{th}} / \Delta K\right]^{p}}{\left[1-\Delta K /(1-r) K_{c}\right]^{q}} .
$$

TABLE 1: Material properties of 304SS.

\begin{tabular}{lc}
\hline Young's modulus $E(\mathrm{MPa})$ & $2.04 \times 10^{5}$ \\
Poisson's ratio $\nu$ & 0.3 \\
Mass density $\rho\left(\mathrm{kg} / \mathrm{m}^{3}\right)$ & 7860 \\
Yield stress $\sigma_{s}(\mathrm{MPa})$ & 275.8 \\
Ultimate stress $\sigma_{b}(\mathrm{MPa})$ & 620 \\
Fracture toughness $K_{C}\left(\mathrm{MPa} \cdot \mathrm{mm}^{0.5}\right)$ & 7645 \\
Threshold value $\Delta K_{\mathrm{th} 0}\left(\mathrm{MPa} \cdot \mathrm{mm}^{0.5}\right)$ & 121.6 \\
\hline
\end{tabular}

TABLE 2: Crack growth properties of 304SS.

\begin{tabular}{lc}
\hline$B$ & $6 \times 10^{-10}$ \\
$p$ & 0.25 \\
$q$ & 0.25 \\
$n$ & 3.0 \\
$S_{\max } / \sigma_{0}$ & 0.3 \\
$\alpha$ & 2.5 \\
\hline
\end{tabular}

The coupling analysis can be done by the above mathematical equations. The stiffness is changed gradually with crack growth first. The damping is also introduced by the friction energy dissipation from crack surfaces. Both of them affect the dynamic response greatly. On the contrary, the crack propagation ratio is also affected by the change of dynamic response.

5.2. Failure Criteria. If the crack depth extends to a certain value or the dynamic stress is too large, alternative failure modes may occur to the beam. Therefore, it is especially important to work out reasonable criteria to indicate the failure. Three failure criteria are considered and shown as follows.

(1) Geometrical Limit. The failure occurs automatically if the crack depth is larger than the half height of the beam, because SIF is not suitable when used to estimate the fatigue life in crack growth equation.

(2) Critical SIF. The fracture occurs if the maximum SIF is larger than critical SIF $\left(K_{I d \max } \geq K_{C}\right)$.

(3) Fracture Failure. The static fracture failure occurs if the maximum value of the bulk dynamic stress is larger than the ultimate strength stress.

\section{Results and Discussion}

A cantilever beam of $304 \mathrm{SS}$ is considered as $1 \mathrm{~m}$ in length, $0.12 \mathrm{~m}$ in width, $0.15 \mathrm{~m}$ in height, and a straight-edge crack with distance $l=0.5 \mathrm{~m}$ from the fixed end. The force that acts on the free end of the cracked beam is a sine excitation. The amplitude of the force is $F_{0}=500 \mathrm{~N}$ and the stress ratio is $r=-1$. The materials of the beam are shown in Table 1 . The crack growth properties of the beam are shown in Table 2.

Because the damping properties in the stainless steel subjected to deformation and temperature, the maximum 


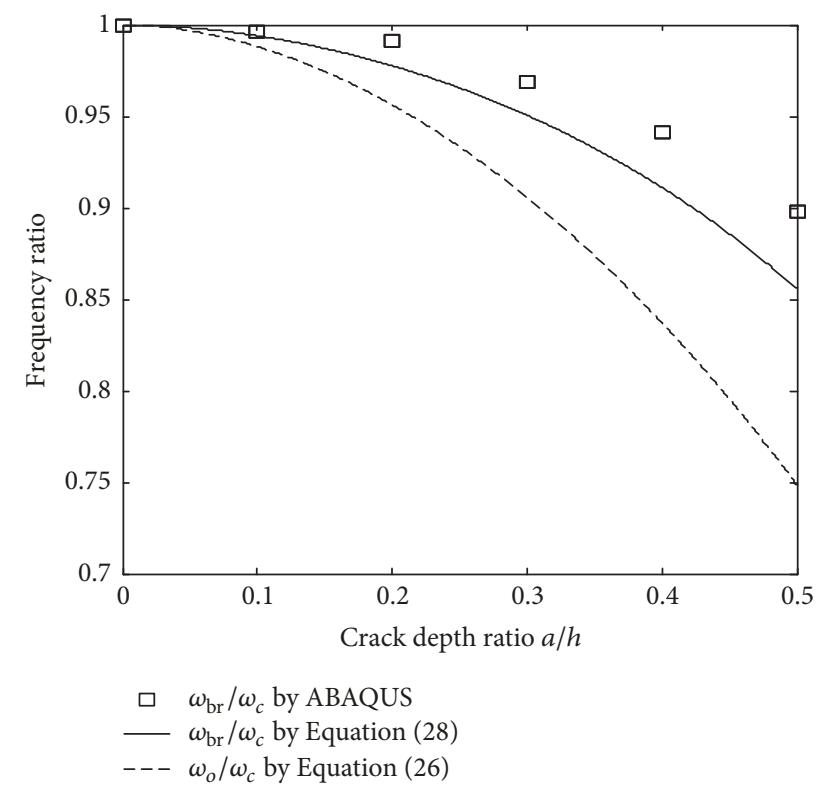

FIGURE 7: Frequencies change with crack severity.

damping loss factor is not bigger than 0.01 [30], and the damping loss factor $\gamma_{m}$ of 304 SS is assumed to be 0.005 . In order to investigate the effects of breathing behaviour on the dynamic response and the crack growth, the mode frequency, friction damping loss factor, dynamic stress, dynamic stress intensity, and crack growth are analyzed.

Figure 7 displays the relation of the mode frequency ratio and the crack depth ratio. Results indicate that the predicted frequency of breathing cracked beam by (28) is in good agreement with the frequency calculated by ABAQUS. The decrease ratio of the frequency of the breathing cracked beam $\omega_{\mathrm{br}} / \omega_{c}$ is smaller than that of the open cracked beam $\omega_{o} / \omega_{c}$. It is implied that if the frequency of the force acted on the beam is near to the resonance frequency, the breathing cracked beam is subjected to a bigger response, because the resonance region of the breathing cracked beam is wider than that of the open cracked beam. Furthermore, the crack growth speed of the breathing crack is faster than that of the open crack near the resonance condition. Therefore, using a breathing crack mode to carry out dynamic analysis or crack growth calculation is more accurate than using an open crack model.

Figure 8 investigates the friction damping loss factor by using different friction coefficient. Results indicate that the friction damping loss factor varies with not only the crack severity but also the friction coefficient. With the increase of the crack depth or the friction coefficient, the friction damping loss factor increases. That implied that the energy dissipated by the friction force is increasing during crack growth. It is very helpful to reduce the dynamic response of the resonant beam. Thus, the crack growth ratio of the breathing crack is reduced too.

Figure 9 shows the maximum dynamic stress of the breathing cracked beam. It is compared with that of the open cracked beam near the resonance region without considering

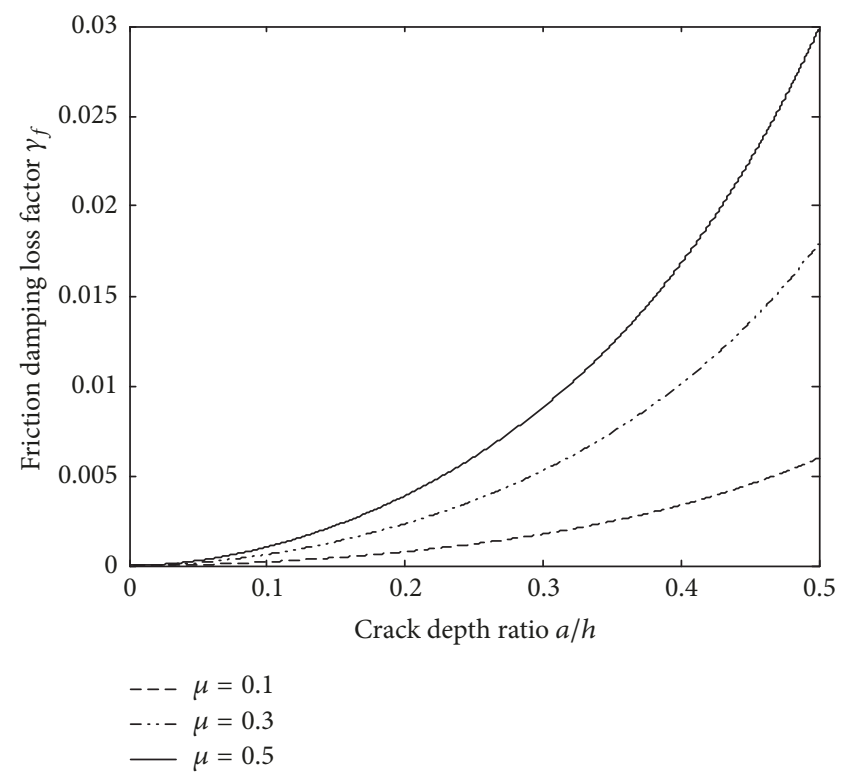

FIgURE 8: Friction damping loss factor with crack severity change under different friction coefficients.

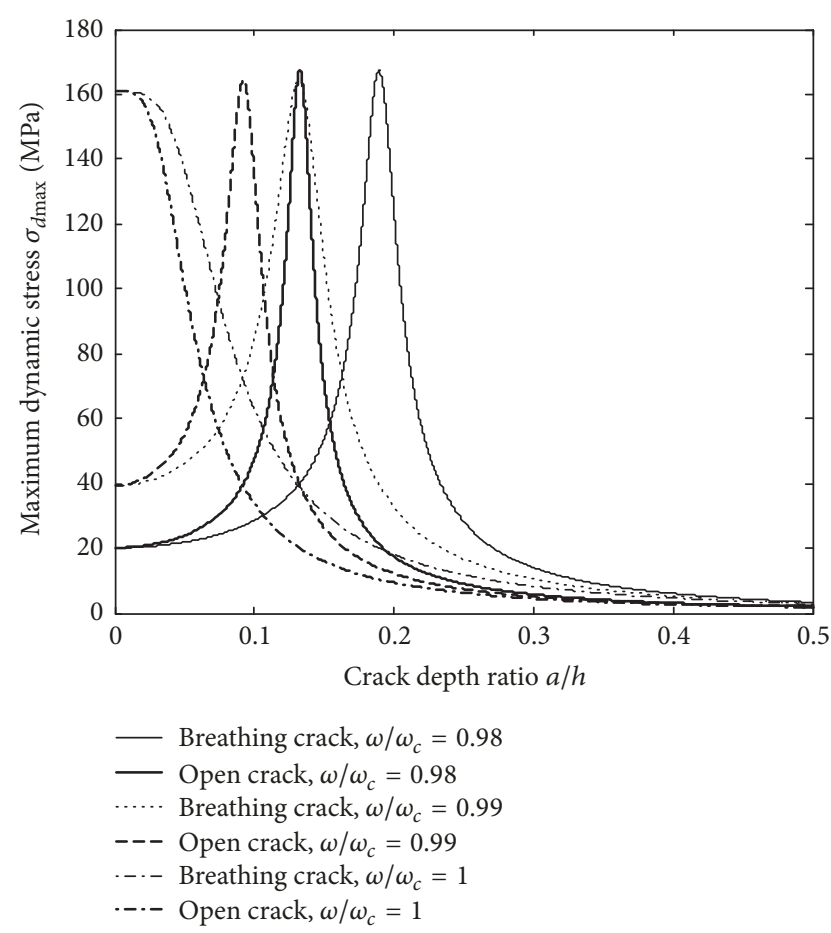

FIgURE 9: The maximum dynamic stress with crack severity change $(\mu=0)$.

the friction damping. Results indicate that the stress response amplitude varies with crack depth. Resonance vibration happens when the crack reaches a certain depth with one fixed exciting frequency. The maximum stress happens at the resonant point. And the maximum dynamic stress of the open cracked beam is smaller than that of the breathing cracked beam with the same exciting frequency. This implies that the 


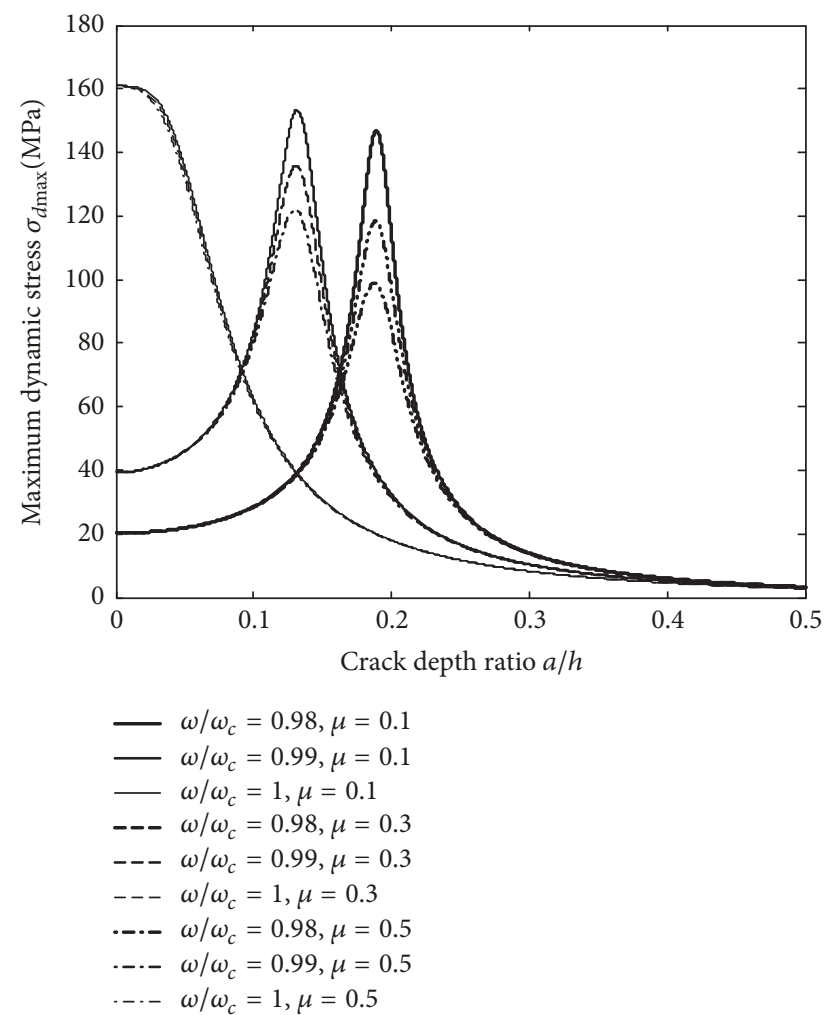

FIGURE 10: The maximum dynamic stress with crack severity change of breathing cracked beam.

closure effect changes the stiffness of the breathing cracked beam so that the maximum stress response also changes.

Figure 10 presents the effect of the friction damping on the maximum dynamic stress of a breathing cracked beam as the beam working under resonance condition. It can be shown that the maximum stress of the beam is greatly reduced by the friction damping. This implied that the friction damping is an important factor to reduce the crack growth ratio.

Figure 11 discovers the relation of the maximum dynamic SIFs of the open cracked beam and that of the breathing cracked beam without friction damping. It is shown that the maximum dynamic SIF of the breathing cracked beam is larger than that of the open cracked beam without friction damping considered under the same exciting frequency. But each of them happens at different crack depths.

Figure 12 studies the effects of friction damping loss factor on the maximum dynamic SIF of the breathing cracked beam at resonance. It can be seen that dynamic SIFs are very sensitive to the friction damping. Comparing Figure 10 with Figure 12, we can find that the change law of the dynamic stress is different from that of the dynamic SIF. The reason is because the crack depth also plays an important role in SIF during crack growth.

Figures 13 and 14 examine the relation of the crack depth with the vibration cycles. It can be seen that the crack growth ratio of the open cracked beam is slower than that of the breathing cracked beam if the friction damping is not considered. The reason is because the decrease ratio of the

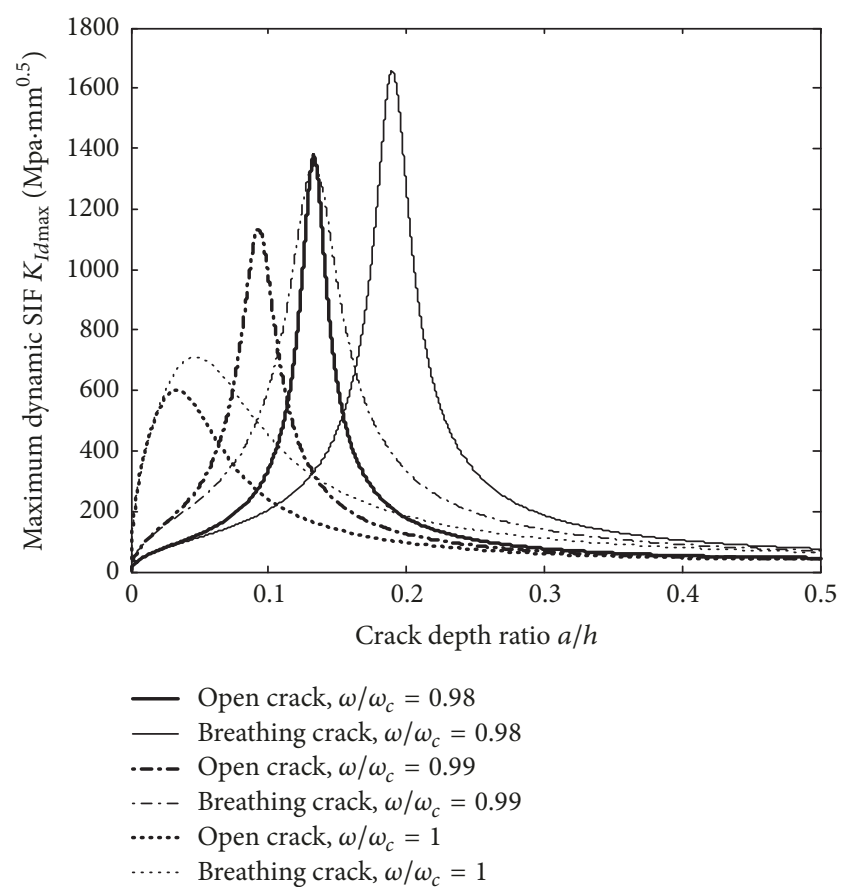

FIGURE 11: The maximum dynamic SIF with crack severity change for different frequency $(\mu=0)$.

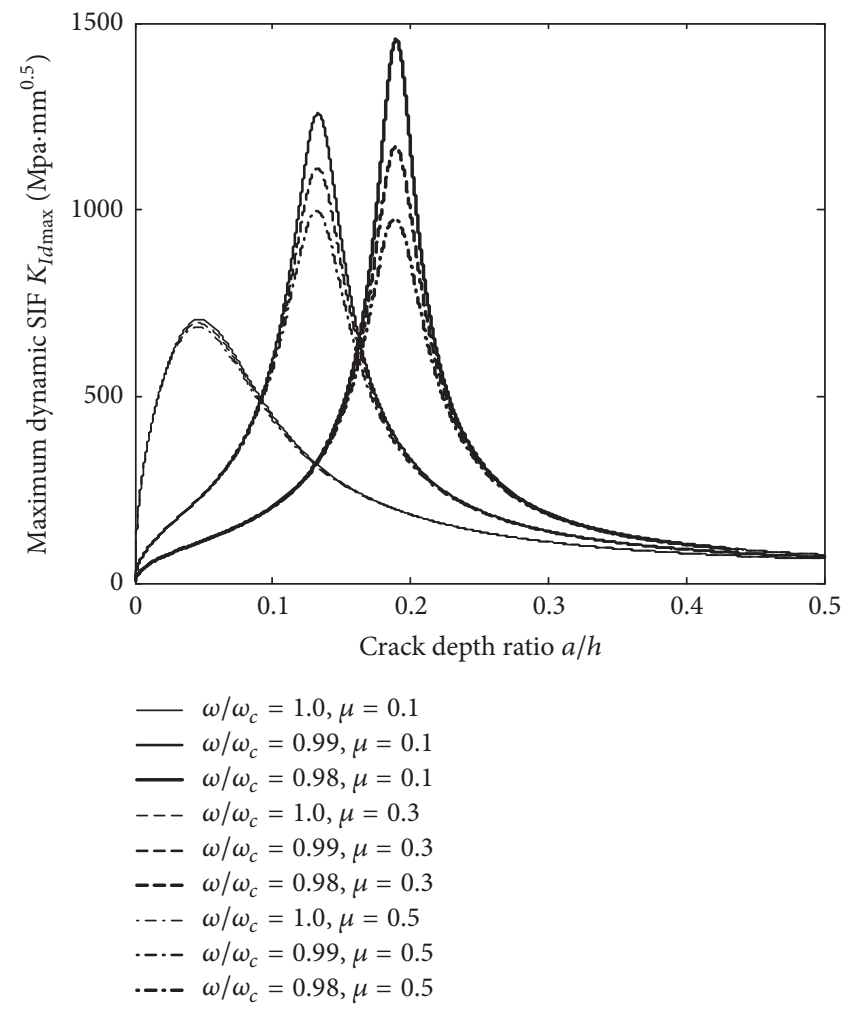

FIGURE 12: The maximum dynamic SIF with crack severity change of breathing cracked beam.

mode frequency of the breathing cracked beam is slower than that of the open cracked beam. This means the breathing cracked beam has a wider resonance region. Considering 


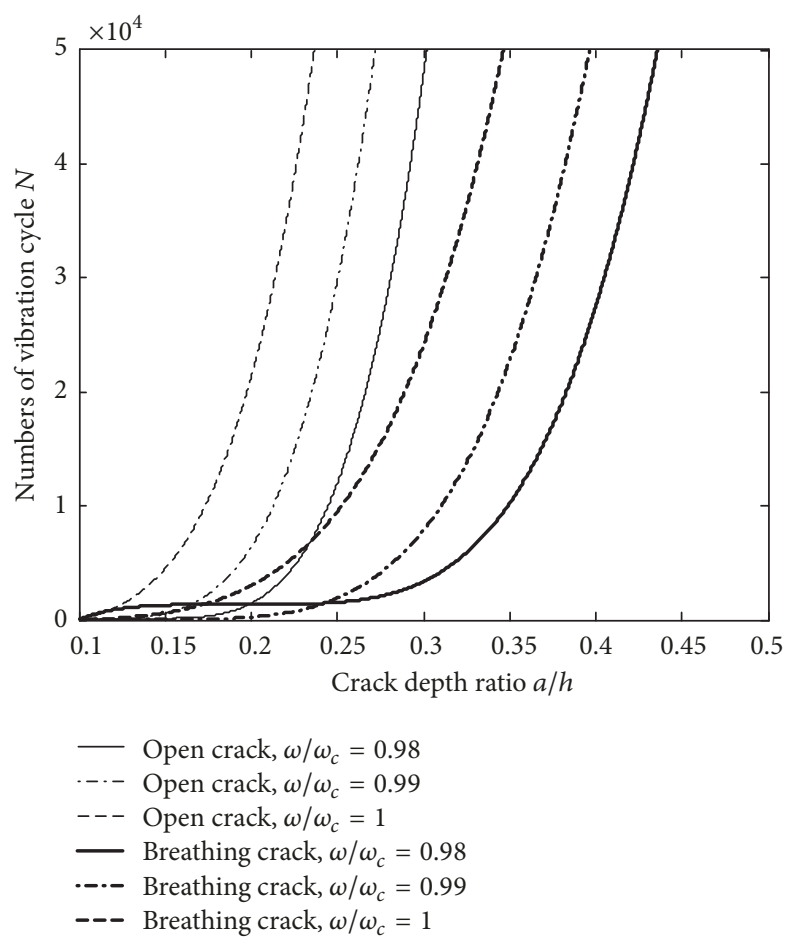

FIGURE 13: Crack depth with vibration cycles for different frequency $(\mu=0)$.

the friction damping, the crack growth ratio is reduced by the friction damping for a breathing cracked beam obviously when the beam comes into resonance region as shown in Figure 14.

Figure 15 shows the relation of the decrease ratio of frequency ratio and the numbers of vibration cycles. It can be seen that the decrease ratio of frequency of the open cracked beam is faster than that of the breathing cracked beam at the first phase of the crack growth when the exciting frequency is 0.98 times of the mode frequency of the intact beam. But after certain numbers of vibration cycle, the decrease ratio of the frequency ratio of the breathing cracked beam is faster than that of the open cracked beam.

\section{Conclusions}

In this article, the stiffness model and the friction damping model of a breathing cracked beam are derived. The first mode frequency is analyzed by using a SDOF model which is simplified by the Galerkin method. The dynamic stress is derived and the crack growth is studied. The effects of the breathing behaviour on the dynamic response and crack growth are revealed so as to analyze the coupling mechanism of the crack growth and dynamic response approximately. The main conclusions are obtained:

(1) During vibration analysis of a cracked beam, the crack closure effect between opening and closing states must be considered. A breathing crack model is better than the open crack model for dynamic response and crack growth analysis. A sinusoidal breathing function is useful to simulate the

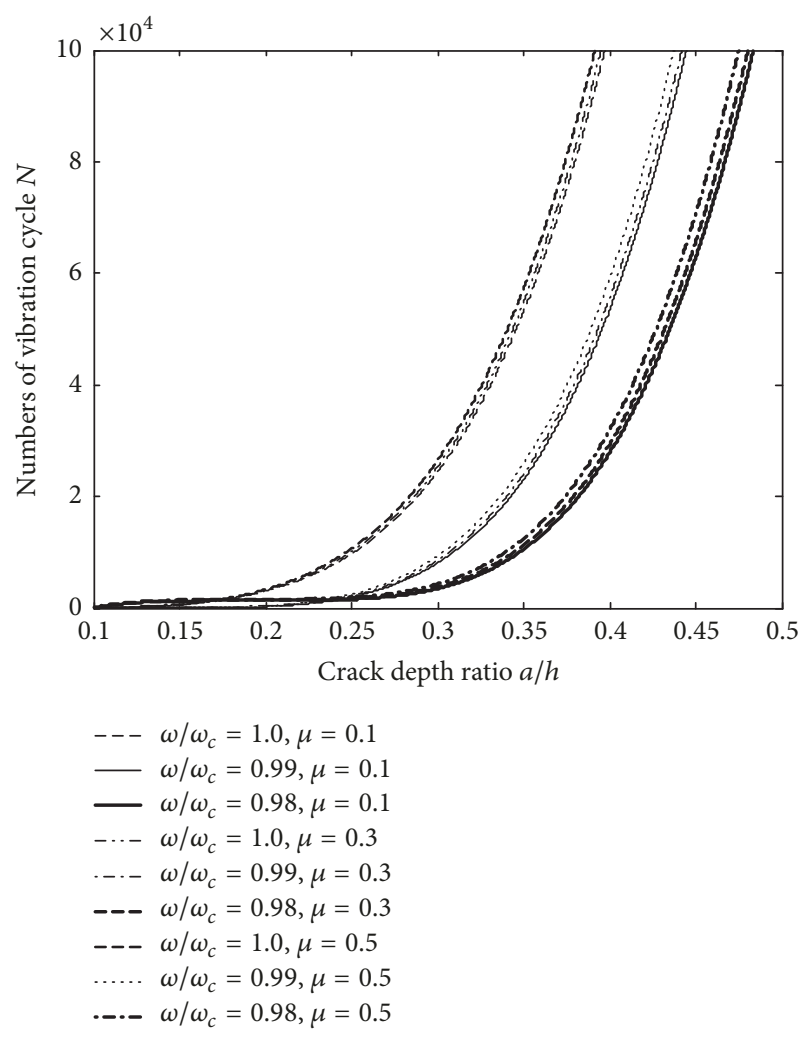

FIGURE 14: Breathing crack depth with vibration cycles for different friction coefficient and frequency.

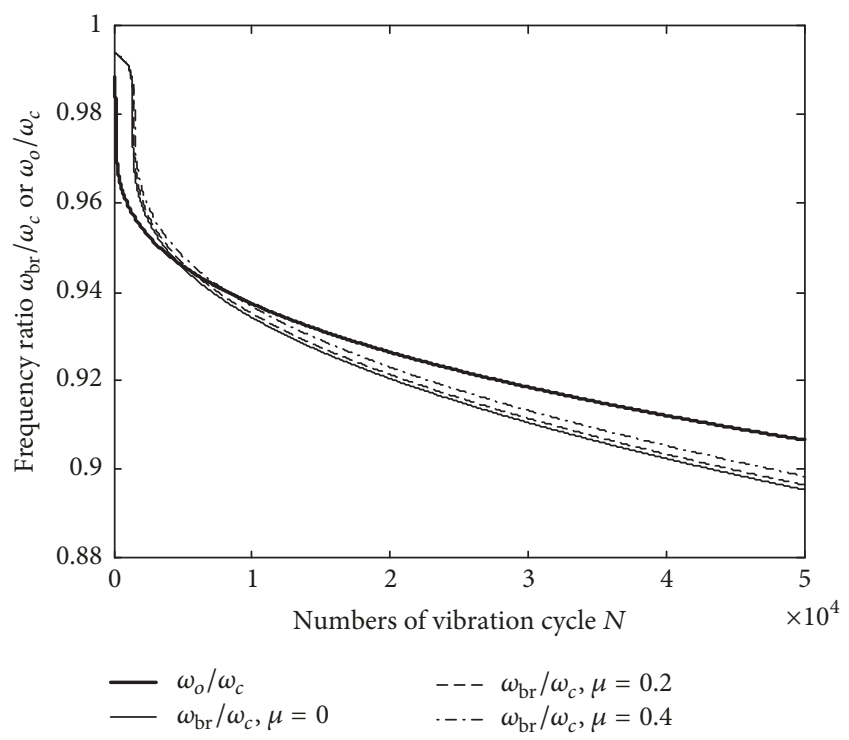

FIGURE 15: Frequency ratio with vibration cycles $\left(\omega / \omega_{c}=0.98\right)$.

transition state between the fully open state and the fully closed state. It meets the object facts and the physical natural of crack. It may be closer to the real motion of the breathing crack than that of the square wave function. Using a breathing crack model is more realistic than using an opening crack model. 
(2) Based on energy principle and Coulomb friction model, the friction model is set up and friction damping loss factor is derived. Friction damping not only plays important role in the maximum dynamic response, but also plays important role in the crack growth. Especially to resonance response and crack growth, friction damping effect is very obvious.

(3) The Galerkin method is used to simplify the breathing cracked beam into a SDOF system. The first mode frequency equation is derived approximately. The first mode frequency changes with the crack severity. The frequency decrease ratio of the breathing cracked beam is slower than that of the open cracked beam. If the closure behaviour of the breathing crack is not considered, the degree of crack growth may be underestimated.

(4) The modified Forman equation is employed to simulate the crack growth. A crack growth life analytical method is proposed with the coupling effect of vibration and fatigue crack growth included. Breathing behaviour of the crack is important to crack growth. The dynamical properties play an important role in crack growth. When the exciting frequency is near to the first mode frequency, the crack growth ratio is very fast. The crack growth life of the breathing cracked beam is smaller than that of the open cracked beam.

\section{Nomenclature}

$a, a_{0}: \quad$ Crack depth, initial crack depth

$a_{i}, \Delta a_{j}$ : The $i$ th step crack depth, the $j$ th step crack incremental

A: $\quad$ Area of cross section

$b$ : $\quad$ Width of beam cross section

$B: \quad$ Fatigue properties of materials

$c^{*}: \quad$ Coefficient of modal damping

$C: \quad$ Flexibility of the intact beam

$C_{T}$ : Flexibility due to the presence of the crack

$C_{o}: \quad$ Total flexibility of the open cracked beam

$d$ : $\quad$ Sliding distance between crack surfaces

$E$ : Young's modulus

$f: \quad$ Closure function of breathing crack

$F$ : $\quad$ Harmonic load

$F^{*}, F_{0}$ : The generalized force, loading amplitude

$F_{n}, F_{f}$ : Normal pressing force, friction force

$F_{\text {av }}: \quad$ Average pressing force

$F_{I}: \quad$ Crack shape function

$h: \quad$ Height of the beam cross section

I: $\quad$ Area moment of inertial of the beam cross section

$k^{*}: \quad$ The generalized stiffness

$k_{\mathrm{br}}: \quad$ Stiffness of the breathing cracked beam

$k_{c}$ : $\quad$ Stiffness of the close cracked beam

$k_{o}$ : $\quad$ Stiffness of the open cracked beam

$k_{T}: \quad$ Stiffness of the torsional spring

$K_{I d}: \quad$ Dynamic stress intensity factor

$K_{I d \max }:$ The maximum dynamic stress intensity factor

$K_{C}: \quad$ Fracture toughness

$\Delta K_{\mathrm{th}}$ : The threshold of stress intensity factor

$\Delta K: \quad$ The range of stress intensity factor

$l$ : $\quad$ Distance of crack from the fixed end
$L: \quad$ Length of the beam

$m^{*}: \quad$ The generalized mass

$M$ : Moment

$n, p, q$ : Fatigue properties of materials

$N$ : Numbers of vibration cycle

Q: $\quad$ Shear force

$r$ : $\quad$ Stress ratio

$t: \quad$ Time

$T: \quad$ Amplitude-time function

$V_{\text {max }}:$ The strain energy

$W_{C}: \quad$ Energy dissipation

$w$ : $\quad$ Lateral deflection in $z$ direction of beam

$W(x)$ : Modal function

$x, y, z$ : The coordinate

$Z_{\mathrm{st}}: \quad$ Static displacement

$\rho, v: \quad$ Density of material, Poisson's ratio

$\mu$ : $\quad$ Friction coefficient

$\omega: \quad$ Excitation frequency

$\omega_{c}: \quad$ Frequency of the close cracked beam

$\omega_{o}$ : Frequency of the open cracked beam

$\gamma_{m}: \quad$ Material damping

$\gamma_{f}: \quad$ Frictional damping

$\eta: \quad$ Amplify ratio

$\lambda: \quad$ Frequency ratio

$\beta$ : The breathing function

$\delta: \quad$ The Dirac function

$\sigma_{n}, \sigma_{d}:$ Nominal stress, normal bulk dynamic stress

$\sigma_{b}, \sigma_{s}:$ Ultimate stress, yield stress.

\section{Conflicts of Interest}

The authors declare that there are no conflicts of interest regarding the publication of this paper.

\section{Acknowledgments}

This research work is supported by the National Natural Science Foundation of China (51565039).

\section{References}

[1] A. R. Biswal, T. Roy, R. K. Behera, S. K. Pradhan, and P. K. Parida, "Finite element based vibration analysis of a nonprismatic Timoshenko beam with transverse open crack," Procedia Engineering, vol. 144, pp. 226-233, 2016.

[2] M. Krawczuk and W. M. Ostachowicz, "Modelling and vibration analysis of a cantilever composite beam with a transverse open crack," Journal of Sound and Vibration, vol. 183, no. 1, pp. 69-89, 1995.

[3] C. A. Papadopoulos and A. D. Dimarogonas, "Coupled longitudinal and bending vibrations of a rotating shaft with an open crack," Journal of Sound and Vibration, vol. 117, no. 1, pp. 81-93, 1987.

[4] W. M. Ostachowicz and M. Krawczuk, "Analysis of the effect of cracks on the natural frequencies of a cantilever beam," Journal of Sound and Vibration, vol. 150, no. 2, pp. 191-201, 1991.

[5] T. G. Chondros and A. D. Dimarogonas, "Vibration of a cracked cantilever beam," Journal of Vibration and Acoustics, vol. 120, no. 3, pp. 742-746, 1998. 
[6] T. G. Chondros, A. D. Dimarogonas, and J. Yao, "A continuous cracked beam vibration theory," Journal of Sound and Vibration, vol. 215, no. 1, pp. 17-34, 1998.

[7] M. Heydari, A. Ebrahimi, and M. Behzad, "Continuous model for flexural vibration analysis of Timoshenko beams with a vertical edge crack," Archive of Applied Mechanics, vol. 85, no. 5, pp. 601-615, 2015.

[8] R. K. Behera, A. Pandey, and D. R. Parhi, "Numerical and experimental verification of a method for prognosis of inclined edge crack in cantilever beam based on synthesis of mode shapes," Procedia Technology, vol. 14, pp. 67-74, 2014.

[9] S. M. Cheng, A. S. J. Swamidas, X. J. Wu, and W. Wallace, "Vibrational response of a beam with a breathing crack," Journal of Sound and Vibration, vol. 225, no. 1, pp. 201-208, 1999.

[10] T. G. Chondros, A. D. Dimarogonas, and J. Yao, "Vibration of a beam with a breathing crack," Journal of Sound and Vibration, vol. 239, no. 1, pp. 57-67, 2001.

[11] E. Douka and L. J. Hadjileontiadis, "Time-frequency analysis of the free vibration response of a beam with a breathing crack," NDT \& E International, vol. 38, no. 1, pp. 3-10, 2005.

[12] M. Kisa and J. Brandon, "Effects of closure of cracks on the dynamics of a cracked cantilever beam," Journal of Sound and Vibration, vol. 238, no. 1, pp. 1-18, 2000.

[13] C. Surace, R. Ruotolo, and D. Storer, "Detecting nonlinear behaviour using the volterra series to assess damage in beamlike structures," Journal of Theoretical and Applied Mechanics, vol. 49, no. 3, pp. 905-926, 2011.

[14] A. Chatterjee, "Nonlinear dynamics and damage assessment of a cantilever beam with breathing edge crack," Journal of Vibration and Acoustics, vol. 133, no. 5, Article ID 051004, 2011.

[15] R. Ruotolo, C. Surace, P. Crespo, and D. Storer, "Harmonic analysis of the vibrations of a cantilevered beam with a closing crack," Computers \& Structures, vol. 61, no. 6, pp. 1057-1074, 1996.

[16] A. Nandi and S. Neogy, "Modelling of a beam with a breathing edge crack and some observations for crack detection," Journal of Vibration and Control, vol. 8, no. 5, pp. 673-693, 2002.

[17] W. Liu and M. E. Barkey, "Nonlinear vibrational response of a single edge cracked beam," Journal of Mechanical Science \& Technology, vol. 31, no. 11, pp. 5231-5243, 2017.

[18] J. Zeng, H. Ma, W. Zhang, and B. Wen, "Dynamic characteristic analysis of cracked cantilever beams under different crack types," Engineering Failure Analysis, vol. 74, pp. 80-94, 2017.

[19] W. Zhang, H. Ma, J. Zeng, S. Wu, and B. Wen, "Vibration responses analysis of an elastic-support cantilever beam with crack and offset boundary," Mechanical Systems and Signal Processing, vol. 95, pp. 205-218, 2017.

[20] H. Ma, J. Zeng, Z. Lang, L. Zhang, Y. Guo, and B. Wen, “Analysis of the dynamic characteristics of a slant-cracked cantilever beam," Mechanical Systems and Signal Processing, vol. 75, pp. 261-279, 2016.

[21] J. Liu, W. D. Zhu, P. G. Charalambides, Y. M. Shao, Y. F. Xu, and X. M. Fang, "A dynamic model of a cantilever beam with a closed, embedded horizontal crack including local flexibilities at crack tips," Journal of Sound and Vibration, vol. 382, pp. 274290, 2016.

[22] Y. S. Shih and J. J. Chen, "Analysis of fatigue crack growth on a cracked shaft," International Journal of Fatigue, vol. 19, no. 6, pp. 477-485, 1997.

[23] A. Dentsoras and A. D. Dimarogonas, "Resonance controlled fatigue crack propagation," Engineering Fracture Mechanics, vol. 17, no. 4, pp. 381-386, 1983.
[24] A. J. Dentsoras and A. D. Dimarogonas, "Resonance controlled fatigue crack propagation in a beam under longitudinal vibrations," International Journal of Fracture, vol. 23, no. 1, pp. 15-22, 1983.

[25] A. J. Dentsoras and A. D. Dimarogonas, "Fatigue crack propagation in resonating structures," Engineering Fracture Mechanics, vol. 34, no. 3, pp. 721-728, 1989.

[26] M. Lalanne, P. Berthier, and J. D. Hagopian, Mechanical Vibrations for Engineers, John Wiley \& Sons, New York, NY, USA, 1983.

[27] A. D. Dimarogonas, S. A. Paipetis, and T. G. Chondros, Analytical Methods in Rotor Dynamics, Springer, Dordrecht, The Netherlands, 2013.

[28] H. Tada, P. C. Paris, and G. R. Irwin, The Stress Analysis of Cracks Handbook, The American Society of Mechanical Engineers, 2000.

[29] J. C. Newman Jr., "A crack opening stress equation for fatigue crack growth," International Journal of Fracture, vol. 24, no. 4, pp. R131-R135, 1984.

[30] R. Mulyukov, S. Mikhailov, R. Zaripova, and D. Salimonenko, "Damping properties of $18 \mathrm{Cr}-10 \mathrm{Ni}$ stainless steel with submicrocrystalline structure," Materials Research Bulletin, vol. 31, no. 6, pp. 639-645, 1996. 


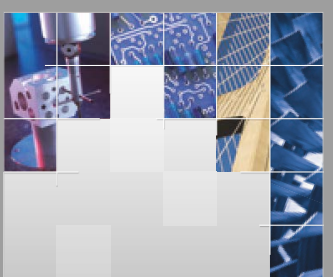

\section{Enfincering}
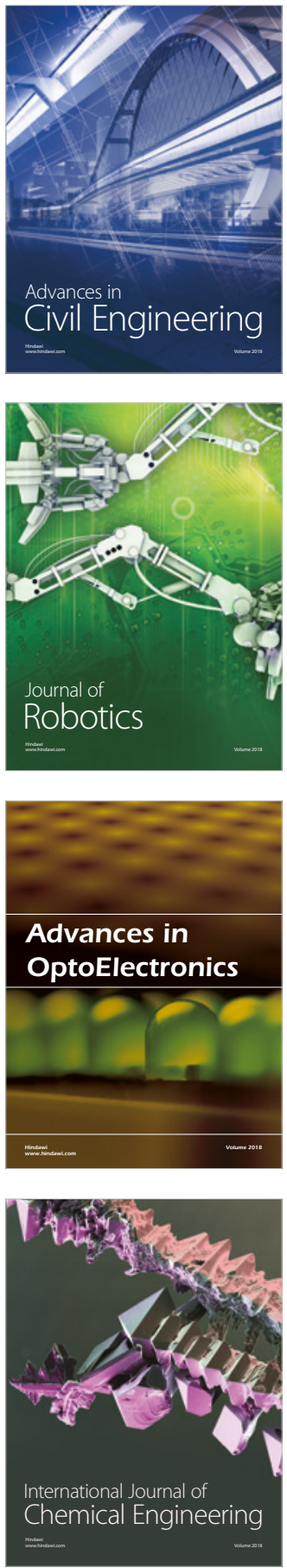

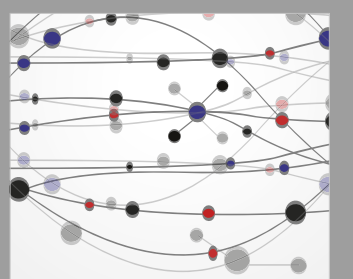

\section{Rotating \\ Machinery}

The Scientific World Journal

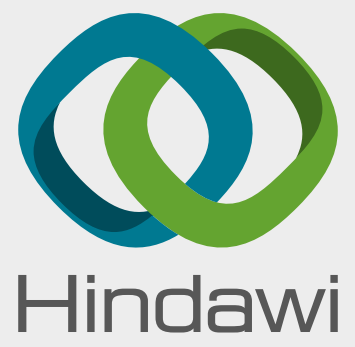

Submit your manuscripts at

www.hindawi.com
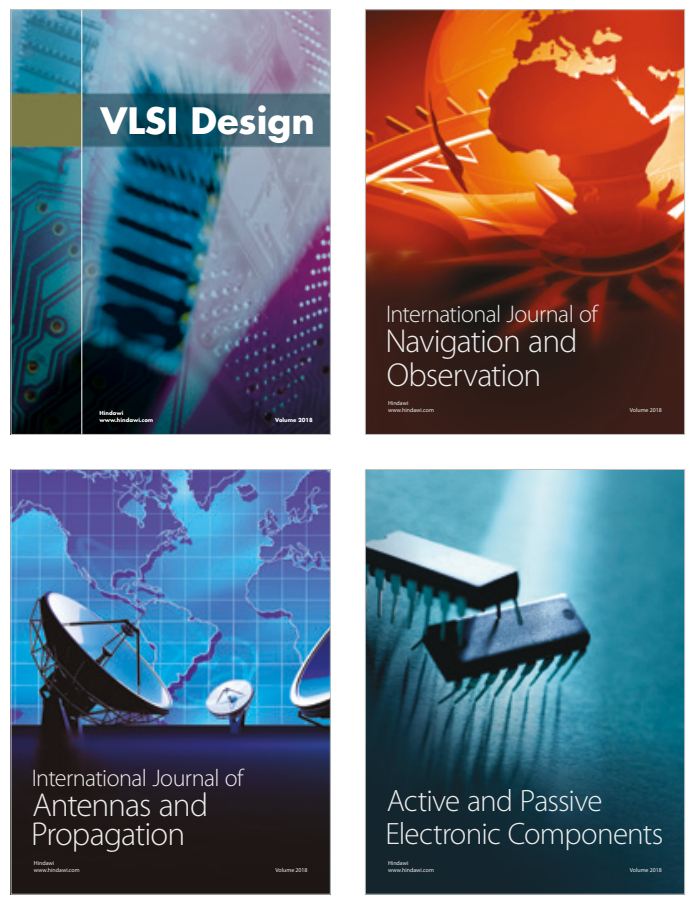
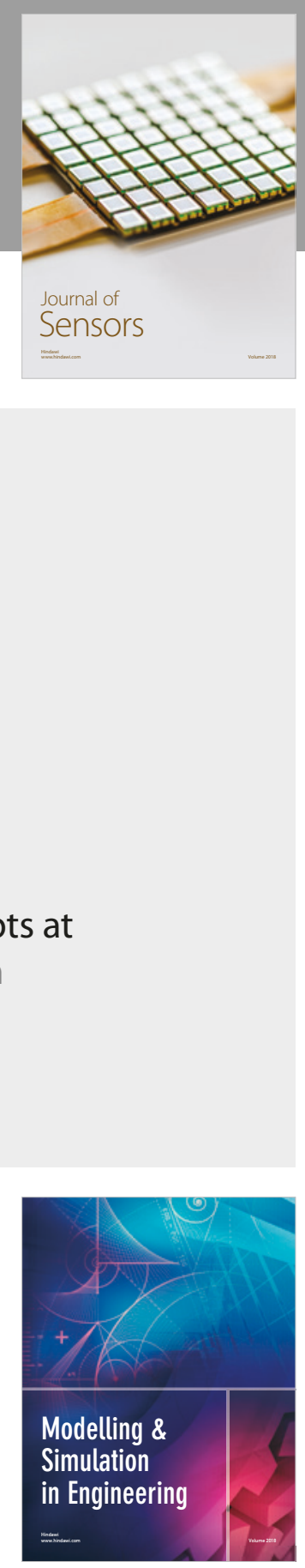

\section{Advances \\ Multimedia}
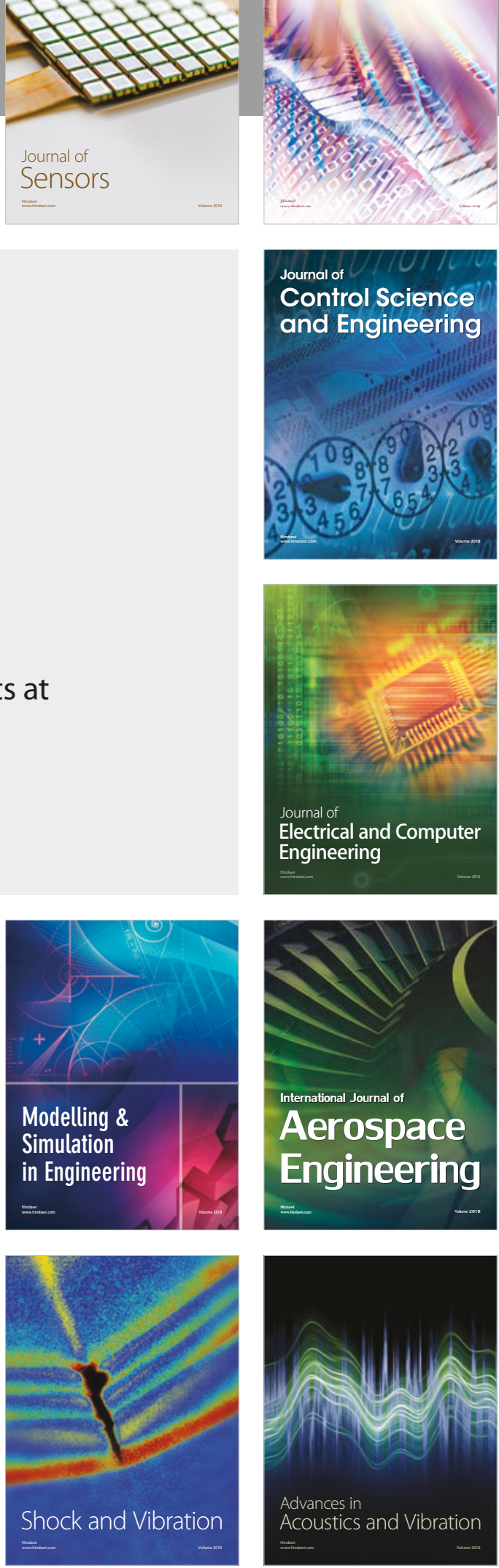